\title{
O PROCESSO DE ENVELHECIMENTO DO SISTEMA NERVOSO E POSSÍVEIS INFLUÊNCIAS DA ATIVIDADE FÍSICA
}

\section{THE AGING PROCESS OF THE NERVOUS SYSTEM AND POSSIBLE INFLUENCES FROM PHYSICAL ACTIVITIES}

\author{
Adilson Sant'Ana Cardoso ${ }^{1 *}$, Adriana Tavares Japiassú ${ }^{2}$, \\ Luciana Sant'Ana Cardoso ${ }^{3}$, Gustavo Levandoski ${ }^{1}$ \\ 1* Autor para contato: Universidade do Estado de Santa Catarina - UDESC, Programa de \\ Pós-Graduação, Mestrado em Ciências do Movimento Humano e Laboratório de \\ Gerontologia (LAGER), Florianópolis, SC, Brasil; (48)96218902; \\ email: cardosoas@gmail.com \\ 2 Universidade do Estado de Santa Catarina - UDESC, Departamento de Educação Física, \\ Florianópolis, SC \\ 3 Especialista em Atividade Física Adaptada pela Universidade Gama Filho - UGF, \\ Rio de Janeiro, RJ \\ Recebido para publicação em 10/12/2007 \\ Aceito para publicação em 08/02/2008
}

\section{RESUMO}

O envelhecimento da população encontra-se em considerável expansão nos países em desenvolvimento. No Brasil, o IBGE estima que em 2020 cerca de $13 \%$ da população terá mais de 60 anos de idade. Com o envelhecimento surgem diversas alterações no homem, como redução do peso e volume cerebral, alterações fisiológicas no sistema cardiovascular, e um maior acometimento por doenças crônico-degenerativas. A busca de respostas para essas alterações tem motivado diversos estudos nas mais diversas áreas. O presente artigo de revisão apresenta dados que abordam o envelhecimento, relacionando-o com o sistema nervoso e com as possíveis contribuições da atividade física no retardamento desse processo. Nesse contexto, reuniram-se dados com a finalidade de atualizar as questões relativas a esse processo, buscando conscientizar profissionais que lidam com idosos a respeito da importância da prática de atividade física regular como fator desencadeador de melhorias na qualidade de vida do idoso, podendo manter ou até mesmo otimizar algumas das funções do sistema nervoso. Diante dos estudos revisados, concluiu-se que a atividade física pode ser considerada um fator moderador das alterações no sistema nervoso. Exercícios de caráter aeróbio parecem ser os mais eficientes, contudo a combinação destes com exercícios de força e flexibilidade parece ser mais eficiente ainda. Assim, encontramse, na literatura internacional, pistas substanciais de que indivíduos físicamente 
ativos possuem uma melhor performance cognitiva, e um envelhecimento cerebral mais saudável do que indivíduos inativos.

Palavras-chave: envelhecimento, sistema nervoso, atividade física.

\begin{abstract}
The aging process of the population is in considerable expansion in developing countries. In Brazil, the IBGE estimates that in the year 2020, around $13 \%$ of the Brazilian population will be over sixty years of age. During the aging process, some alterations appear in humans, such as a reduction in the weight and volume of the brain, physiological alterations in the cardiovascular system, and a higher incidence of chronico-degenerative pathologies. The search for causes for these alterations has motivated studies in several different areas. The present review article presents data on the aging process, relating it with the nervous system and with the possible contributions of physical activities in slowing down this process. With this purpose, a literature review of studies addressing this matter was performed with the aim to make professionals who work with elderly people aware of the importance of the regular practice of physical activities as a triggering factor to improve the erderly person's quality of life, while keeping, or even enhancing, some functions of their nervous system. This literature review evinced that physical activities can be considered a moderating factor on the changes of the nervous system. Aerobic exercises seem to be the most effective, but when associated with strength and flexibility exercises they are even more effective. Thus, the international literature presents substantial clues which prove that physically active individuals have a higher cognitive performance, and a healthier brain aging as compared to inactive individuals.
\end{abstract}

Key words: aging, nervous system, physical activity

\section{Introdução}

O aumento da expectativa de vida tem revelado o surgimento de déficits e alterações neurológicas degenerativas que evoluem com o avanço da idade (BERNHARDI M., 2005). Pois, após atingir a sua maturidade, o sistema nervoso começa a sofrer o impacto do processo de envelhecimento e como conseqüência os idosos passam a apresentar, de forma progressiva, sintomas de deficiências motoras, psicológicas e sensoriais. Este processo acentua-se podendo resultar na morte, simultânea, do indivíduo e de seu sistema nervoso (LENT, 2001).

A possível influência da atividade física sobre funções cerebrais do idoso foi discutida por diversos autores (KALSHA, 1997; SHEPHARD, 2003; MCAULEY, KRAMER e COLCOMBE, 2004; KRAMER et al., 2005). Os exercícios físicos promovem, no homem, benefícios no funcionamento neural, aumento do metabolismo neuronal (KALSHA, 1997), melhora da cognição, das estruturas e funções cerebrais (MCAULEY, KRAMER e COLCOMBE, 2004; KRAMER et al., 2005), também melhora a quantidade de oxigênio e glicose cerebral, acelera a remoção dos restos necrosados de neurônios e tonifica alguns sistemas de neurotransmissores. Kramer et al. (2005) sugerem ainda que mesmo processos bastante susceptíveis ao envelhecimento podem ser amenizados pelo 
treinamento físico. É provável ainda que a atividade física regular diminua a ansiedade e a depressão, aumente a auto-estima, otimize o estímulo cerebral (POON citado por SHEPHARD, 2003) e focalize a atenção (STELMACH citado por SHEPHARD, 2003).

Neste contexto, esta revisão pretende reunir informações, abordando o processo de envelhecimento do sistema nervoso, as principais alterações e o papel da atividade física como meio de diminuição e prevenção das alterações cerebrais decorrentes do avanço da idade. Para tal foram revisados 30 artigos científicos (9 nacionais e 21 internacionais) publicados entre os anos de 1993 e 2006, coletados nas bases de dados da Scielo, Scientific Direct e Pubmed, e por meio do Scholar Google, e 21 livros publicados entre os anos de 1988 e 2003 disponíveis nas bibliotecas da Universidade do Estado de Santa Catarina (UDESC) e Universidade do Vale do Itajaí (UNIVALI).

Inicialmente será apresentada uma discussão acerca de algumas hipóteses sobre as causas do envelhecimento do sistema nervoso, seguida de uma caracterização de algumas alterações encontradas na literatura provocadas pelo envelhecimento no sistema nervoso. E, por fim será realizada uma discussão acerca do papel da atividade física como fator moderador deste processo decorrente do avanço da idade.

\section{Hipóteses para o envelhecimento do Sistema Nervoso (SN)}

Diante das alterações sofridas pelo sistema nervoso, em virtude do processo de envelhecimento, algumas hipóteses de possíveis causadores de tais mudanças são descritas na literatura.

Uma das correntes destas hipóteses centra-se na idéia de que o envelhecimento é resultado do acúmulo passivo de alterações nos ácidos nucléicos das células (MORA e PORRAS, 1998). Um dos principais processos para estas alterações no DNA seria a acumulação de moléculas danificadas por radicais livres (MORA e PORRAS, 1998), os quais são formados através de complexas reações químicas que quebram as moléculas livres de oxigênio $\left(\mathrm{O}_{2}\right)$ formando moléculas simples deste elemento químico $\left(\mathrm{O}_{2}\right)$ que são altamente reativas e tendem a ligar-se com quaisquer outras moléculas que encontrem (HAYFLICK, 1997), o que é prejudicial ao sistema nervoso, pois segundo conclusão do estudo de Giovannelli et al. (2003), este sistema é altamente vulnerável ao dano oxidativo.

$\mathrm{O}$ aumento no número de radicais livres nas células do sistema nervoso pode ocorrer em função vários fatores, dos quais, segundo Bernhardi M. (2005), destacam-se: o alto consumo de oxigênio pelo cérebro (cerca de $20 \%$ de todo oxigênio consumido, segundo Hayflick (1997)), a dependência do metabolismo aeróbio de carboidratos, a complexa formação lipídica em suas membranas e a diminuição da capacidade de eliminar estas moléculas de radicais livres, ou seja, a diminuição dos mecanismos antioxidantes, a qual étalvez um dos fatores mais influentes (MORA e PORRAS, 1998).

O acúmulo de radicais livres é ainda responsável pela aglomeração de pigmentos (lipofucsina) nas células, pela formação de placas neuríticas, e responsável por determinadas ligações cruzadas capazes de afetar o DNA (HAYFLICK, 1997). Estas ligações cruzadas com o processo de envelhecimento tendem a aumentar seu número, afetando a ligação entre algumas proteínas, dentre elas o colágeno, impedindo processos metabólicos através da obstrução da passagem de nutrientes e resíduos para dentro e fora da célula. Contudo, as ligações cruzadas são, provavelmente, mudanças bioquímicas relacionadas à idade, e não parecem ser o fator mais contribuinte para este processo (HAYFLICK, 1997).

O acúmulo de erros no DNA pode se dar não somente pela ação dos radicais livres, mas também em virtude da transcrição do DNA em RNA não ocorrer com total confiabilidade, gerando assim certos erros que dão lugar a proteínas não funcionais. Apesar dos níveis de erro nesta transcrição parecerem não aumentar com a idade (MORA e PORRAS, 1998), Lent (2001), relata que essas sucessivas mutações, espontâneas ou provocadas ao longo da vida, acabariam por esgotar os genes redundantes a determinados fenótipos, gerando assim a degeneração morfofuncional do sistema nervoso interligada ao envelhecimento.

Esse princípio parte de uma teoria onde é postulada a redundância gênica, que aponta a existência de múltiplos genes para cada fenótipo, sendo alguns 
redundantes para tal. Todavia as alterações no DNA decorrentes deste processo tendem a se acumular e reproduzir através das clonagens posteriores (BERNHARDI M., 2005). Derivada da idéia das alterações no DNA, Mora e Porras (1998) relatam a teoria do encurtamento dos telómeros, que induz a idéia de que em cada divisão celular poderia ocorrer uma perda de certa parte do DNA. No entanto, ainda não está clara a sua associação com o envelhecimento.

A outra corrente das hipóteses sobre o envelhecimento do sistema nervoso centra-se na idéia de que o envelhecimento éresultado de um programa genético (MORA e PORRAS,1998).

Lent (2001) cita um experimento de Hayflick, onde em placas de cultura de tecidos, foi contado o número de vezes que os fibroblastos conseguiam se dividir. Foram então comparados os fibroblastos de diferentes espécies e verificou-se que os de camundongos se dividiam menos que os de humanos e, que estes por sua vez, se dividiam menos que os de tartaruga (sabe-se que as tartarugas vivem mais que os homens e estes por sua vez mais que os camundongos). Através deste experimento Hayflick sugeriu a existência de um relógio biológico que controlaria o tempo de vida das células, não sendo a idade cronológica totalmente responsável por este.

Para Mora e Porras (1998), esta teoria é baseada nos exemplos de morte celular programada, que ocorrem durante todo processo de desenvolvimento. Este fenômeno de morte celular ocorre em todo o sistema nervoso, não sendo exclusivo dos humanos. A este fenômeno é dado o nome de apoptose, ou seja, um processo ativo de "suicídio” celular, que se dá através da síntese de proteínas cuja função é matar a célula (LENT, 2001).

Segundo Mora e Porras (1998), têm-se proposto mecanismos moleculares do envelhecimento que reúnem diversas hipóteses, aceitando-se que este processo está, em parte, programado geneticamente, porém, este “programa” é susceptível a modificações.

\section{Alterações no sistema nervoso decorrentes do envelhecimento}

Lent (2001) refere-se ao cérebro do idoso como sendo, em média, de tamanho e peso menores, giros mais finos separados por sulcos mais abertos e profundos o que resulta em regiões corticais menores em comparação a cérebros de indivíduos jovens. Ou seja, com o avanço da idade o peso do cérebro humano diminui (MORIGUCHI E MORIGUCHI, 1988; HAYFLICK, 1997; MORA e PORRAS, 1998; BORGE, HERNÁDEZ e EGEA, 1999; LENT, 2001; OLIVEIRA 2001; CANÇADO E HORTA, 2002) chegando a uma redução em torno de 10\% (HAYFLICK, 1997; MORA e PORRAS, 1998; CANÇADO E HORTA, 2002).

Esse declínio apresenta-se mais precocemente na mulher do que no homem (CANÇADO e HORTA, 2002). Uma explicação para este evento pode estar relacionada ao declínio do estrógeno nas mulheres a partir da menopausa. Em ratas, os níveis de estrógeno estão relacionados à densidade das espinhas dendríticas, ao número de espinhas e sinapses (BERNHARDI M., 2005). Erickson et al. (2006) indicam que os níveis de estrógeno estão associados à neuroproteção, ao crescimento e à função neural.

Seguindo este processo, o volume cerebral também sofre uma diminuição (MORIGUCHI E MORIGUCHI, 1988; HAYFLICK, 1997; MORA e PORRAS, 1998; BORGE, HERNÁDEZ e EGEA, 1999; LENT, 2001; OLIVEIRA 2001; CANÇADO E HORTA, 2002). A magnitude desta diminuição seria de aproximadamente $2 \%$ por década a partir dos cinqüenta anos (MORA e PORRAS, 1998; BORGE, HERNÁDEZ e EGEA, 1999). Caso analisada através da comparação do volume cerebral com a caixa craniana, este permaneceria constante até a meia-idade (93\%), onde por volta dos sessenta anos apresentaria um declínio discreto com posterior acentuação entre os setenta e noventa anos, podendo chegar a $80 \%$. O volume cerebral pode diminuir até $200 \mathrm{~cm} 3$. (CANÇADO E HORTA, 2002).

Acompanhando esta redução, de peso e volume, observam-se mudanças anatômicas em diversas estruturas do sistema nervoso. O quadro 1 apresenta de forma mais clara algumas destas alterações, derivadas do avanço da idade, relacionando-as aos autores que as citaram. 
Quadro 1 - Alterações anatômicas decorrentes do envelhecimento.

\begin{tabular}{|c|c|c|c|c|c|c|}
\hline $\begin{array}{c}\text { Autor/ } \\
\text { Estrutura }\end{array}$ & $\begin{array}{c}\text { Borge, } \\
\text { Hernádez e } \\
\text { Egea, } 1999\end{array}$ & Hayflick, 1997 & $\begin{array}{c}\text { Mora e } \\
\text { Porras, } 1998\end{array}$ & Lent, 2001 & Oliveira, 2001 & $\begin{array}{c}\text { Cançado e } \\
\text { Horta, } 2002\end{array}$ \\
\hline $\begin{array}{c}\text { Sulcos } \\
\text { corticais }\end{array}$ & Aumento & Ampliação & $\begin{array}{c}\text { Aumento do } \\
\text { tamanho }\end{array}$ & $\begin{array}{c}\text { Mais abertos e } \\
\text { profundos }\end{array}$ & Dilatados & $\begin{array}{l}\text { Alargamento e } \\
\text { aprofundamento }\end{array}$ \\
\hline Giros & Diminuição & Redução & $\begin{array}{c}\text { Diminuição do } \\
\text { tamanho }\end{array}$ & Mais finos & - & $\begin{array}{l}\text { Redução da } \\
\text { largura }\end{array}$ \\
\hline $\begin{array}{l}\text { Ventrículos } \\
\text { cerebrais }\end{array}$ & Dilatação & - & $\begin{array}{l}\text { Aumento do } \\
\text { volume }\end{array}$ & - & Dilatados & $\begin{array}{l}\text { Alargamento e } \\
\text { aumento do } \\
\text { volume }\end{array}$ \\
\hline Fissuras & - & - & - & - & Amplas & Alargamento \\
\hline $\begin{array}{c}\text { Cisternas } \\
\text { basais }\end{array}$ & - & - & - & - & Dilatadas & Alargamento \\
\hline $\begin{array}{c}\text { Substância } \\
\text { Branca }\end{array}$ & - & - & $\begin{array}{l}\text { Diminuição do } \\
\text { volume }\end{array}$ & - & \begin{tabular}{|c|} 
Redução, \\
gerando a \\
"Leucariose", \\
\end{tabular} & $\begin{array}{l}\text { Redução, } \\
\text { gerando a } \\
\text { "Leucariose" }\end{array}$ \\
\hline Meninges & - & - & - & - & - & Espessamento \\
\hline $\begin{array}{c}\text { Espaços } \\
\text { Perivasculares } \\
\text { (Virchow- } \\
\text { Robin) }\end{array}$ & & - & - & - & $\begin{array}{c}\text { Aumentam de } \\
\text { tamanho e } \\
\text { quantidade }\end{array}$ & - \\
\hline
\end{tabular}

Fontes: BORGE, HERNÁDEZ e EGEA, 1999; HAYFLICK, 1997; MORA e PORRAS, 1998; LENT, 2001; OLIVEIRA, 2001; CANÇADO e HORTA, 2002.

Alguns pesquisadores apontam que durante 0 processo de envelhecimento existe uma perda progressiva das células nervosas (HAYFLICK, 1997; MORA e PORRAS, 1998; CARVALHO FILHO e PAPALÉO NETTO, 2000; LENT, 2001; SHEPHARD, 2003) e/ ou uma retração neuronal (MORA E PORRAS, 1998; GRILL e RIDDLE, 2002; CANÇADO E HORTA, 2002), caracterizando uma certa atrofia cerebral (MORIGUCHI e MORIGUCHI, 1988; MORA e PORRAS, 1998; CARVALHO FILHO e PAPALÉO NETTO, 2000; CANÇADO E HORTA, 2002).

Essa redução ocorre por morte celular, principalmente, no córtex dos giros pré-centrais, nos giros temporais (HAYFLICK, 1997; MORA e PORRAS, 1998; CARVALHO FILHO e PAPALÉO NETTO, 2000), e no córtex do cerebelo (CARVALHO FILHO e PAPALÉO NETTO, 2000; CANÇADO e HORTA, 2002), hipocampo, amígdala, substância negra, núcleos hipotalâmicos (MORA e PORRAS, 1998) núcleos de base, tálamo, tronco cerebral (núcleo facial), medula espinhal. Enquanto que as alterações por redução de tamanho das células ocorrem mais na substância branca e corpo caloso, e no tronco cerebral (núcleo coclear). Este processo de perda neuronal (e/ou retração) parece ocorrer em todo o córtex, porém não se apresenta da mesma forma nas diversas regiões (CANÇADO e HORTA, 2002), variando de intensidade e não ocorrendo necessariamente ao mesmo tempo. Confirmando este argumento, Grill e Riddle (2002), em seu estudo com ratos, encontraram que as alterações dendríticas relacionadas à idade ocorrem com extraordinária especificidade. Em neurônios do hipocampo a perda pode ser de 3 a $9 \%$ por década, no cerebelo a magnitude desta perda se dá em torno de 2,5\% das células de Purkinje por década, e na substância negra passa de 1,4\% entre os quinze e os sessenta e cinco anos, para $11 \%$ entre os sessenta e cinco e oitenta e cinco anos (MORA e PORRAS, 1998).

Esta redução neuronal acaba alterando as conexões entre os neurônios (AZEVEDO, 2003), os quais têm fundamental importância nos processos neurais, pois são os responsáveis pela transmissão de impulsos elétricos, através das sinapses, que ocorrem 
na presença de neurotransmissores, ou mensageiros químicos (FOSS; KETEYIAN, 2000). Assim, em função dessas alterações, a velocidade de condução nervosa é reduzida (HEATH, 1994), tendo uma queda de 15\% entre os cinqüenta e oitenta anos (BORGE, HERNÁDEZ e EGEA, 1999) ou, segundo Vargas (2001), de 1 a 15\% até os sessenta anos.

Dentre as mudanças morfológicas (ou funcionais?) provocadas pelo processo de envelhecimento no sistema nervoso, as alterações em dendritos e sinapses tornam-se relevantes em virtude de sua importância no processo de formação e manutenção da memória e na chegada de informação aos neurônios (BORGE, HERNÁDEZ e EGEA, 1999). A diminuição progressiva da árvore dendrítica e, em conseqüência, das sinapses, é uma das causas da atrofia cerebral. Essa diminuição parece ocorrer de forma heterogênea (MORA e PORRAS, 1998). Porém, de forma paralela à morte neuronal, ocorre um crescimento da árvore dendrítica. Este aumento dendrítico é um mecanismo compensador conhecido como plasticidade neural e, atua de forma mais eficaz até a sétima década de vida diminuindo nas décadas seguintes (MORA e PORRAS, 1998; CANÇADO e HORTA, 2002).

Alterações dendríticas podem refletir em uma diminuição da densidade sináptica sendo este processo geralmente acompanhado da degeneração dos axônios mielínicos (BERNHARDI M., 2005). Para o autor, por conseqüência destas alterações mielínicas ocorre uma redução na conectividade cortical o que, ao invés da perda de neurônios, estaria associada a déficits cognitivos. Segundo Morrison e Hof, citados por Bernhardi M. (2005), as alterações sinápticas, relacionadas aos circuitos do hipocampo, ocorrem por alteração do perfil molecular ou por perda das sinapses. Os autores concluíram que as alterações sinápticas relacionadas à idade têm caráter estrutural ou de mudanças moleculares, mas sem necessariamente ocorrer perdas neuronais.

Ocorre uma queda de 50\% nas sinapses do córtex motor pré-central a partir da oitava década de vida, com simultâneo aumento das sinapses restantes (mecanismo compensador), e redução de $20 \%$ dos terminais pré-sinápticos após os sessenta anos (CANÇADO e HORTA, 2002).

Apesar de ocorrerem estas perdas neuronais, o cérebro tem propriedades das quais faz uso para diminuir o grau destas mudanças adversas relacionadas ao avanço da idade (CANÇADO e HORTA, 2002).

Primeiramente, o fato de existirem mais células nervosas do que é necessário é definido por Cançado e Horta (2002) como redundância. Para os autores, o sistema nervoso central é constituído de 14 a 20 bilhões de neurônios, outros autores, como Hayflick (1997) e Lent (2001) entram em conflito com este dado sugerindo a existência de 100 bilhões de neurônios. Todavia, não se sabe ao certo o número de células necessárias, impossibilitando assim que se avalia a extensão da redundância (CANÇADO e HORTA, 2002).

A plasticidade neural é a outra propriedade que o cérebro tem para amenizar a passagem do tempo, sendo um mecanismo compensador. Esta é a capacidade adaptativa das estruturas e funções do sistema nervoso em função de interações com o ambiente externo e/ou interno, e ainda como resultado de lesões (FERRARI, 2001). A plasticidade atua de forma a contrabalançar a degeneração neural (SCHALLERT e WOODLEE, 2003). Hayflick (1997) afirma que a plasticidade permite aos neurônios criar novas conexões, desenvolver-se e criar novas sinapses, restaurando ou compensando, assim, circuitos reduzidos ou rompidos (CANÇADO e HORTA, 2002). O alcance da plasticidade cerebral não parece ser influenciado pela idade, podendo assim, a plasticidade ser estimulada inclusive em idosos (BHERER et al, 2006).

Lent (2001) indica a existência de várias formas de plasticidade, sendo estas: de regeneração, plasticidade axônica, dendrítica, sináptica e somática. A plasticidade de regeneração é a capacidade de recuperar axônios lesados; a plasticidade axônica permite que os terminais axônicos de neurônios sadios possam reorganizar sua distribuição de acordo com estímulos do ambiente; também os dendritos sadios têm essa capacidade, que se manifesta nos troncos, ramos e espinhas dendríticas, sendo a chamada plasticidade dendrítica; quando as sinapses fazem uso de aumentos ou diminuições na transmissão sináptica ocorre a plasticidade sináptica; e por fim a plasticidade somática que é a capacidade de regular a proliferação ou morte de células nervosas.

As células da neuróglia permitem o bom funcionamento dos neurônios, pois suas funções oferecem a infra-estrutura necessária para tal (LENT, 2001). Relacionado ao envelhecimento das células da glía, 
Mora e Porras (1998) afirmam que o componente destas células tende a aumentar. Ocorre um aumento no número de astrócitos (CANÇADO e HORTA, 2002; MOUTON et al., 2002; BERNHARDI M., 2005), nas regiões de atrofia dos giros (CANÇADO e HORTA, 2002). Em um estudo com camundongos, Mouton et al. (2002) encontraram um aumento no número da micróglia e dos astrócitos de cerca de 20\%, comparando-se fêmeas mais velhas às jovens. As fêmeas mais velhas apresentaram, ainda, cerca de 25 $40 \%$ de astrócitos e micróglia a mais, no giro denteado e CA1, do que os machos mais velhos. Os autores atentam ainda para o fato de os astrócitos e a micróglia serem alvos dos hormônios gonodais, induzindo assim à idéia de que os efeitos dos hormônios sexuais e da idade reprodutora poderiam ser responsáveis por este processo. Contudo, Bernhardi M. (2005) ressalta que estas alterações gliais ocorrem de forma primária, não sendo derivadas de outras alterações provocadas pelo envelhecimento. Com isso, poder-se-ia dizer que o incremento da neuróglia tem um papel central no envelhecimento, ou que este decorre de algum outro processo ainda desconhecido? Questiona o autor.

O processo de envelhecimento resulta, ainda, em outras alterações bioquímicas, histológicas e fisiológicas que podem ser, ou não ser, agentes ativos do envelhecimento, ou apenas processos resultantes deste. Para Mora e Porras (1998), estas alterações microscópicas parecem ser resultados da degeneração neuronal. Contudo, Bernhardi M. (2005) afirma que o processo de involução do sistema nervoso está relacionado em grande parte com alterações degenerativas funcionais, e não com morte celular, sendo estas alterações decorrentes na maioria das vezes de mudanças químicas no cérebro (AZEVEDO, 2003; GEIS, 2001, LENT, 2001).

Mora e Porras (1998) apontam a relação do envelhecimento com o aumento do conteúdo cerebral de DNA que, segundo os autores, poderia ser resultado da proliferação do conteúdo glíal. Já a quantidade de RNA tende a diminuir apenas nos neurônios, mantendo seus níveis nas células gliais.

Lent (2001) afirma que o cérebro tende a envelhecer por uma dificuldade crescente de sintetizar substâncias essenciais ao seu funcionamento e função neuronal - um decréscimo, entre trinta e noventa anos, de 5 a 25\% do conteúdo cerebral de proteínas (MORA e PORRAS, 1998), e pelo aumento da síntese e acumulação de substâncias anômalas resultado de alterações na sua degradação (sendo a principal destas o peptídeo $\beta$-amilóide) que se depositam no tecido (MORA e PORRAS, 1998; LENT, 2001).

Decorrente disto, duas alterações podem ser citadas. A primeira é a formação dos emaranhados neurofibrilares, os quais se compõem da proteína " $t a u$ " e de outras proteínas associadas ao citoesqueleto, uniquitina e $\beta$-amilóide. Estes emaranhados acabam alterando as funções celulares por causarem a perda do citoesqueleto normal de microtúbulos e neurofilamentos (CANÇADO e HORTA, 2002). Tendem a aparecer freqüentemente no córtex cerebral, temporal e hipocampo (MORA e PORRAS, 1998). A segunda alteração ocorre, pois a síntese protéica deficitária e o aumento no depósito de substâncias anômalas, acabam por provocar a degeneração celular, acumulando fragmentos celulares nos emaranhados neurofibrilares, e por fim estas, células, rompem-se formando detritos que se aglomeram em placas senis. O depósito destas placas senis tende a aumentar com o avanço da idade, porém varia muito entre indivíduos na mesma faixa etária. Este processo é acentuado pelo fato de o sistema imunológico e a neuróglia, serem também afetados pelo envelhecimento, gerando uma incapacidade de remoção destes detritos (LENT, 2001). Estes últimos tendem a se acumularem no lobo temporal, no neocórtex cerebral e em algumas estruturas subcorticais (CANÇADO e HORTA, 2002).

Uma das “marcas” do envelhecimento na célula nervosa é a presença do pigmento lipofucsina, este pigmento também é observado em células cardíacas, do fígado e do músculo estriado em extremidades paralisadas ou imobilizadas. Resulta da perioxidação dos lipídios poliinsaturados das membranas biológicas (MORA e PORRAS, 1998). São grânulos intracitoplasmáticos e acumulam-se nos neurônios, células da glía e no endotélio capilar, sendo encontrados no núcleo olivar inferior, núcleo denteado do cerebelo, núcleos do tálamo, globo pálido, núcleo rubro, núcleos motores de pares cranianos e nos grandes neurônios do giro pré-central (CANÇADO e HORTA, 2002). Ainda não está claro o efeito do acúmulo de lipofucsina sobre a função neural (HAYFLICK, 1997; 
CANÇADO e HORTA, 2002), se esta pode produzir dano ou é resultado dos mesmos (MORA e PORRAS, 1998).

A chamada degeneração grânulo-vacuolar é a presença de pequenos vacúolos, isolados ou múltiplos no pericário celular, parecendo ser resultado de um processo de autofagia celular, e consiste na degradação da proteína tau nos lisossomos. Ocorre na região ântero-medial do lobo temporal (CANÇADO e HORTA, 2002).

Cançado e Horta (2002) citam ainda a presença de corpos de Hirano nas células piramidais do hipocampo e subiculum. Todavia estes corpos são mais notados em pessoas portadoras da doença de Alzheimer.

Uma das principais causas da deterioração cognitiva com o passar da idade éo declínio significativo dos neurotransmissores. Como a síntese de proteínas é afetada com o passar da idade, e a ação dos neurotransmissores se dá através de enzimas e receptores de membranas (proteínas) as alterações em neurotransmissores podem daí decorrer - mudanças funcionais (BERNHARDI M., 2005), ou serem resultados da atrofia e morte neuronal (MORA e PORRAS, 1998). Contudo, Cançado e Horta (2002) indicam que o efeito destas alterações ainda não está bem estabelecido.

Ocorre uma diminuição, principalmente, dos níveis de acetilcolina, dopamina e serotonina, ácido gama-aminobutírico (GABA) (quadro 2) e das endorfinas (KHALSA, 1997) e nos receptores colinérgicos (CANÇADO e HORTA, 2002). Os níveis de noradrenalina apresentam dados conflitantes, para Khalsa (1997) ocorre uma redução, Mora e Porras (1998) citam que há alteração, porém não se refere nem à diminuição, nem ao aumento, que é citado por Cançado e Horta (2002). Essa variação pode ser explicada pelos diferentes anos das pesquisas e assim, por conseqüentes avanços nas técnicas de avaliação.

Quadro 2 - Alterações de alguns neurotransmissores associados com o envelhecimento.

\begin{tabular}{|c|c|c|c|}
\hline Neurotrasmissor & Autores & Alterações Indicadas & Região* \\
\hline Acetilcolina & $\begin{array}{c}\text { Khalsa, 1997; Mora E } \\
\text { Porras, 1998; Oliveira E } \\
\text { Furtado, 1999; Cançado E } \\
\text { Horta, 2002 }\end{array}$ & Diminui & $\begin{array}{l}\text { Núcleo basal de Meyert e } \\
\text { córtex }\end{array}$ \\
\hline Dopamina & \begin{tabular}{|c} 
Moriguchi E Moriguchi, \\
1988; Khalsa, 1997; Mora \\
E Porras, 1998; Cançado E \\
Horta, 2002 \\
\end{tabular} & Diminui & $\begin{array}{l}\text { Substância negra e núcleo } \\
\text { caudado }\end{array}$ \\
\hline \multirow{2}{*}{ Noradrenalina } & Khalsa, 1997; & Diminui & \multirow{2}{*}{ Córtex e lócus ceruleus } \\
\hline & Cançado e Horta, 2002 & Aumento & \\
\hline Serotonina & $\begin{array}{c}\text { Khalsa, 1997; Oliveira E } \\
\text { Furtado, 1999; Cançado E } \\
\text { Horta, 2002 }\end{array}$ & Diminui & Córtex e núcleos de rafe \\
\hline GABA & \begin{tabular}{|c|} 
Moriguchi E Moriguchi, \\
1988; Oliveira E Furtado, \\
1999; Cançado E Horta, \\
2002
\end{tabular} & Diminui & $\begin{array}{l}\text { Núcleo olivar inferior e } \\
\text { núcleo caudado }\end{array}$ \\
\hline
\end{tabular}

Fontes: Moriguchi e Moriguchi, 1988; Khalsa, 1997; Mora e Porras, 1998; Cançado e Horta, 2002.

$\left(^{*}\right)$ - dados segundo Cançado e Horta, 2002. 
Essa redução de neurotransmissores afeta várias regiões do encéfalo, sobretudo no tronco encefálico e em regiões onde terminam os axônios dopaminérgicos e noradrenérgicos (núcleos da base, hipotálamo e córtex cerebral) (OLIVEIRA E FURTADO, 1999), e acetilcolinérgicas (MORA e PORRAS, 1998). Nas vias dopaminérgicas é verificado ma diminuição da densidade dos receptores dopaminérgicos, e uma alteração significativa nos níveis de dopamina a partir dos setenta e cinco anos no corpo estriado. As vias apresentam diminuição nos receptores acetilcolinérgicos no corpo estriado, e também da enzima acetilcolina-transferase, responsável pela síntese da acetilcolina no córtex cerebral, corpo estriado e hipocampo (MORA e PORRAS, 1998).

Muitas destas alterações são observadas tanto em indivíduos acometidos de patologias, como naqueles onde o processo de envelhecimento ocorre de forma normal (HAYFLICK, 1997; MORA e PORRAS, 1998; LENT, 2001; CANÇADO e HORTA, 2002). Este ponto, segundo Mora e Porras (1998), é um fator que dificulta a investigação científica acerca do processo de envelhecimento do sistema nervoso, visto que muitas vezes não é possível diferenciar se uma alteração se deve ao envelhecimento em si, ou ao acometimento de alguma patologia concomitante. Somando-se a isso, a variabilidade do processo de envelhecimento de um indivíduo para outro também é substancial (CANÇADO e HORTA, 2002). Sendo assim, buscou-se expor, neste artigo, alterações decorrentes de um processo de envelhecimento normal, sem centrar-se em alterações patológicas, apesar de muitas vezes ser difícil definir normal e patológico.

As principais patologias que acometem o sistema nervoso em indivíduos idosos são: o acidente vascular cerebral, as demências e as doenças degenerativas de Alzheimer e Parkinson. No sistema nervoso periférico as neuropatias ou neurites são as moléstias mais comuns, todas elas afetando os processos de formação e manutenção da memória (AZEVEDO, 2003). Ainda algumas doenças sistêmicas possuem efeito negativo, como é o caso da Diabetes mellitus (hiperglicemia, e dano oxidativo), das alterações endócrinas (perda do efeito neutrófico de vários hormônios), a hipertensão arterial (dano vascular) (BERNHARDI M., 2005), e quadros hipoglicêmicos graves (podendo gerar alterações na função cerebral) (LEHNINGER, 1990).
As alterações que ocorrem no sistema nervoso provocam conseqüências nas funções cerebrais durante o envelhecimento. Diversos autores citam alterações nas capacidades cognitivas (HAYFLICK, 1997; KARUZA, 1997; MORA e PORRAS, 1998; BORGE, HERNÁDEZ e EGEA, 1999; CARVALHO FILHO e PAPALÉO NETO, 2000; CANÇADO e HORTA, 2002; SHEPHARD, 2003), sensitivas (HAYFLICK, 1997; MORA e PORRAS, 1998; BORGE, HERNÁDEZ e EGEA, 1999) e motoras (LEXELL, 1997; MORA e PORRAS, 1998; OLIVEIRA E FURTADO, 1999; VARGAS, 2001; DOHERTY et al., 2003).

No que diz respeito às alterações motoras percebe-se que alterações nas unidades motoras apresentam maior relevância ao se analisar o movimento humano. Lexell (1997) descreve que o avanço da idade afeta as unidades motoras, principalmente o motoneurônio inferior, e que este processo, decorrente da degeneração do sistema nervoso, é uma das principais causas da diminuição de massa e força muscular. Doherty et al. (1993), confirmam esta idéia, pois indicam que a redução de força muscular associada ao avanço da idade é resultado da perda de unidades motoras. Tomlinson e Irving, citados por Lexell (1997), sugerem que a perda de motoneurônios parece ser uniforme, sendo uma redução de $25 \%$ da segunda até a décima década de vida, embora seja citado que muitas pessoas acima de sessenta anos apresentem 50\% menos motoneurônios do que em idades mais jovens. Em sua revisão Lexell (1997) cita ainda estudos que indicam: diminuição do número das fibras nervosas grandes e médias, com uma perda de $5 \%$ da juventude à velhice, e redução do diâmetro das fibras grandes (KAWAMURA et al.; MITTAL e LOGMANI); alteração na amplitude e duração do potencial de ação das unidades motoras (HAYWARD; HOWARD et al.), com diminuição da amplitude e aumento da duração (MORIGUCHI e MORIGUCHI, 1988); e redução da velocidade de condução (BORGE, HERNÁDEZ e EGEA, 1999) de impulsos de todos motoneurônios (DOHERTY et al. citados por LEXELL, 1997) e aumento do tempo de latência estímulo-resposta com o avançar da idade (MORIGUCHI E MORIGUCHI, 1988).

Apesar do processo de envelhecimento do sistema nervoso acarretar uma deficiência em todo 
processo de transmissão de impulsos nervosos, Häkkinen, Kallinen e Komi citados por Fleck e Kraemer (1999) indicam que se há uma incapacidade nos idosos em ativar seus músculos ao máximo, esta incapacidade está relacionada aos mecanismos neuromusculares periféricos, e não à função dos impulsos neurais reduzidos. O que induz à idéia de que a redução das estruturas neurais pode vir a afetar mais o desempenho do sistema sensório-motor, do que um déficit no processo de transmissão de impulsos nervosos no SNC. Porém, em estudos de Oda, e de Wokke et al., ambos citados por Lexell (1997), foram encontrados, com o avanço da idade, um aumento no comprimento das placas terminais (ODA; WOKKE et al.), aumento no número de axônios pré-sinápticos (ODA), e aumento nas ramificações da membrana pós-sinápticas (WOKKE et al.).

Contudo os mecanismos subjacentes destas mudanças não estão bem determinados, podendo estas ocorrer apenas como um mecanismo compensatório para a manutenção das funções neuromotoras, devido a um processo de desenervação/re-inervação relacionado ao envelhecimento e que ocorre pela redução da capacidade funcional das unidades motoras. O processo de re-inervação consegue até certo ponto compensar a desenervação, porém como o processo de degeneração do sistema nervoso tende a serem contínuos e, aos poucos mais fibras vão se tornando desenervadas (LEXELL, 1997).

A diminuição da massa e da força muscular que pode ser de até $20 \%$ na sexta década de vida segundo Vargas (2001) - se dá por perda e/ou redução do tamanho das fibras musculares, afetando principalmente as fibras de tipo IIb - de contração rápida (LEXELL, 1997). Häkkinen, Kallinen e Komi citados por Fleck e Kraemer (1999) relacionaram a perda de fibras musculares à morte de células musculares (danos irreversíveis) ou como resultado da perda de contato com o nervo (desenervação). Quando o processo de desenervação supera o processo de re-inervação ocorre a atrofia muscular relacionada ao envelhecimento, onde as fibras musculares são substituídas por gordura e tecidos fibrosos (LEXELL, 1997).

A intensidade destas alterações fisiológicas causadas pelo envelhecimento depende significativamente de fatores ligados ao estilo de vida que a pessoa assume em seu histórico de vida. Nesse sentido,
Leite (2000) afirma que, apesar das perdas funcionais, orgânicas e mentais, um idoso que tenha tido hábitos de vida saudáveis pode vir a ser uma pessoa com autosuficiência para tarefas diárias e com capacidade adaptada para manter relações intelectuais e sociais com o meio que o rodeia. O benefício de um histórico de vida rico (com experiências e estímulos ambientais variados), é reforçado por Ferrari et al. (2001), que ao realizarem um estudo de revisão, expõem o fato de que em diferentes idades a exposição do indivíduo (cobaias não humanas) a estes ambientes resulta em adaptações específicas do sistema nervoso central (SNC), como: aumento na espessura das camadas do córtex visual, no tamanho de corpos neuronais e de núcleos dos corpos neuronais, no número de sinapses e na área das zonas de contato sináptico, no número de dendritos e de espinhas dendríticas, no volume e no peso cerebral, além de alterações em níveis de neurotransmissores (ROSENZEWEIG, 1996; WELKER et al., 1991; citados por FERRARI et al., 2001).

Outro fator que possui influência na intensidade com a qual estas mudanças irão acometer o indivíduo é relacionada à sua dieta. Os possíveis benefícios de uma dieta de restrição calórica são bem aceitos na literatura, contudo alguns autores apresentam certos aspectos negativos desta. Sendo assim, de forma breve, serão apresentados alguns aspectos positivos e negativos deste controle dietético.

A dieta de restrição calórica é sugerida por Hayflick (1997) como responsável por retardar o envelhecimento, através do retardamento do cronômetro hipotalâmico do cérebro. Estudos mais recentes (CALINGASAN e GIBSON, 2000; MATTSON, 2000; SHI et al. 2002; BERNHARDI M., 2005; RESUEHR e OLCESE, 2006) vão um pouco mais além e indicam que uma dieta restrita pode induzir a: redução do estresse oxidativo - modulando a extensão dos danos oxidativos no cérebro, diminuição da neurodegeneração, aumento da produção de fatores neutróficos, aumento da plasticidade cerebral e da capacidade de auto-reparação, aumento do período de vida do indivíduo.

Entretanto para Resuehr e Olcese (2006) a dieta restrita possui aspectos tanto positivos, como também aspectos negativos. Shi et al. (2002), analisaram o efeito da dieta restrita no córtex sensoriomotor de ratos com 29 meses de idade. Estes ratos apresentaram uma 
redução na densidade numérica das sinapses inibitórias, a densidade de sinapses relacionadas com a densidade de neurônios também apresentou uma diminuição, quando comparados com ratos que não tiveram restrição na dieta. Os autores concluíram que a dieta de restrição calórica falhou em prevenir o declínio, relacionado à idade, tanto nas sinapses inibitórias, quanto nas sinapses excitatórias.

Todavia, é aceito que a dieta restrita é um fator contribuinte para a manutenção de um bom funcionamento do sistema nervoso, contudo não é unanimidade, e futuras pesquisas devem ser realizadas.

\section{Atividade física e o sistema nervoso no idoso}

Diversos pesquisadores (KALSHA, 1997; MATTSON, 2000; HANNA et al., 2001; SHEPHARD, 2003; KELIM, JONES e SCHALLERT, 2003; SCHALLERT A WOODLEE, 2003; MCAULEY, KRAMER e COLCOMBE, 2004; NETZ et al., 2005; KRAMER et al., 2005; VANCE et al., 2005; KRAMER, ERICKSON e COLCOMBE, 2006) relatam a influência da atividade física na saúde do sistema nervoso, das funções cognitivas e sua importância para a plasticidade neural.

Stones e Kozma citados por Costa (2004), e Mcauley, Kramer e Colcombe (2004), confirmaram um melhor desempenho cognitivo dos indivíduos fisicamente ativos sobre os sedentários. Em um estudo de meta-análise sobre exercício, cognição e envelhecimento cerebral, Kramer, Erickson e Colcombe (2006) citam que os estudos encontrados na literatura apontam uma significante, e muitas vezes substancial, relação inversa entre os níveis de atividade física e o declínio cognitivo relacionado ao envelhecimento.

Em contrapartida, estes mesmos autores Kramer, Erickson e Colcombe (2006) - citam dois estudos - Yamada et al., e Wilson et al. - onde esta relação (citada anteriormente) não foi encontrada. A causa dessa discordância nos resultados pode ser explicada através de alguns estudos (ETNIER et al. citados por MATSUDO, 2000; MCAULEY, KRAMER e COLCOMBE, 2004; KRAMER et al., 2005; KRAMER, ERICKSON E COLCOMBE,
2006) que indicam que uma pequena inconsistência pode ser observada em alguns resultados obtidos da relação entre exercício físico, aptidão física e cognição, pois estes resultados dependem dos exercícios, dos participantes, da percentagem de mulheres na amostra, dos testes cognitivos, da qualidade do estudo, dos diferentes tipos de treinamento físico e protocolos de avaliação, diferentes avaliações cognitivas, dificuldade de excluir idosos com sinais sub-clínicos de demência, influência de fatores genéticos e pequenos períodos de acompanhamento da amostra. Todavia, os fatores que afetam os resultados ainda não foram totalmente elucidados (KRAMER, ERICKSON E COLCOMBE, 2006).

Contudo, alguns pesquisadores (COLCOMBE et al., 2003; MCAULEY, KRAMER e COLCOMBE, 2004; KRAMER et al., 2005) sugerem uma relação bastante confiável entre atividade e exercício físico, e diversos processos cognitivos.

Muitas das pesquisas relacionando a aptidão física com o sistema nervoso, e cognição, utilizaram-se de cobaias não-humanas, porém, os dados de animais não-humanos são, segundo Kramer et al. (2005), compatíveis com os dados de pesquisas em humanos, em estudos relacionando aptidão física, performance, função e estruturas cerebrais.

Pesquisas em animais, citadas por Mcauley, Kramer e Colcombe (2005), sinalizam diversas alterações no sistema nervoso destas cobaias, dentre elas: mudanças morfológicas na estrutura cerebral - rede dendrítica, desenvolvimento capilar, desenvolvimento de novos neurônios, e mudanças neuroquimícas (ROSENZWEIG e BENNETT); animais treinados aerobicamente apresentam maior densidade dos capilares no cerebelo e em outras áreas cerebrais, enquanto animais treinados com habilidades motoras apresentaram um maior número de sinapses no cerebelo (BLACK et al.; SWAIN et al.); proliferação celular, sobrevida celular e neurogênese no hipocampo (VAN PRAAg et al.). É sugerido por Van Praag et al., ainda citado por Mcauley, Kramer e Colcombe (2005), que o exercício físico em animais velhos pode produzir benefícios tanto na cognição, quanto na proliferação neuronal. Mattson (2000), aponta também, além da neurogênese, o aumento da produção de fatores neurotróficos. O aumento na produção destes fatores 
neurotróficos pode induzir a produção de proteínas antioxidantes, estabilizar a homeostase de cálcio, e inibir a apoptose.

Os exercícios físicos têm comprovada importância, para a saúde cerebral e cognitiva, promovendo, no homem, benefícios no funcionamento neural, aumento do metabolismo neuronal (KALSHA, 1997), melhora da cognição, das estruturas e funções cerebrais (MCAULEY, KRAMER e COLCOMBE, 2004; KRAMER et al., 2005), também melhora a quantidade de oxigênio e glicose cerebral, acelera a remoção dos restos necrosados de neurônios e tonifica alguns sistemas de neurotransmissores. Kramer et al. (2005) sugerem ainda que mesmo processos bastante susceptíveis ao envelhecimento podem ser amenizados pelo treinamento físico.

Uma das alterações morfológicas mais observadas no sistema nervoso do idoso é a perda de tecido (MORA e PORRAS, 1998; CARVALHO FILHO e PAPALÉO NETTO, 2000; CANÇADO E HORTA, 2002). Kramer e Madden (2006), citam que declínios relacionados ao envelhecimento são freqüentemente observados na integridade e volume das substâncias branca e cinzenta, tanto nos gradientes anteriores, como nos posteriores. Uma forma de ir contra, reduzindo ou amenizando, este processo é o aumento na aptidão aeróbica.

Colcombe et al. (2003), realizaram um estudo em que analisaram imagens de ressonância magnética de alta resolução, relacionando a variação da densidade do tecido neural com a idade, aptidão aeróbica e outros indicadores de saúde, em uma amostra de 55 idosos. Os resultados deste estudo apontaram que ocorreu menor perda de substância cinzenta nos lobos frontal, parietal e temporal, e menor perda nos tratos anterior e posterior da substância branca nos indivíduos mais aptos aerobicamente. Indicando que os níveis de aptidão aeróbica contribuem de forma moderadora nesta perda de tecidos, inclusive agindo nas partes mais afetadas pelo envelhecimento.

Carvalho Filho e Papaléo Netto (2000) apontam estudos que demonstram um mal desempenho de indivíduos idosos em tarefas que requisitam iniciativa, planejamento, avaliação, e coordenação de tarefas - o chamado controle executivo (KRAMER et al. 1999) , e que estas habilidades declinam significativamente com o envelhecimento (WEST et al. citado por
MCAULEY, KRAMER e COLCOMBE, 2004). Contudo, foram encontrados dados substanciais, na literatura, que apontam para a associação entre os níveis de aptidão aeróbica com tarefas que envolvam o controle executivo (KRAMER et al, 1999; MCAULEY, KRAMER e COLCOMBE, 2004; KRAMER et al., 2005; KRAMER, ERICKSON E COLCOMBE, 2006).

Como já citado anteriormente, o número de mulheres na amostra, sendo este maior $50 \%$, pode interferir de forma positiva nos resultados a serem obtidos. Erickson et al. (2006) indicam que o exercício físico e os níveis dos marcadores bioquímicos de estrógeno têm mecanismos similares, ambos associados a neuroproteção (níveis de BDNF - do inglês "brain derived neurotrophic factor" - afetados pela interação entre exercício e tratamento à base de estrógeno), crescimento e função neural. A associação entre os níveis de BDNF e o exercício físico é também apontada por Mcauley, Kramer e Colcombe (2004), porém em roedores.

Em sua pesquisa, Erickson et al. (2006), realizaram um interessante estudo, com 54 mulheres idosas com idade média de 69, 61 anos, em estado pósmenopausal, sobre a interação entre exercício físico e terapia de reposição hormonal (TRH), e seus efeitos na saúde cerebral. Estes autores confirmaram a associação positiva entre exercício físico e TRH. Os resultados obtidos indicam que: os benefícios provindos da prática de exercícios físicos não são dependentes dos níveis de estrógeno, visto que, no estudo, as idosas que não realizavam TRH obtiveram benefícios na cognição e volume cerebral por serem ativas fisicamente; a TRH de longa duração (acima de 16 anos) parece ter um efeito negativo tanto na cognição, quanto nos tecidos cerebrais, entretanto o estudo sugere que o aumento nos níveis de aptidão física pode compensar os efeitos negativos da TRH de longa duração; e finalmente, a combinação entre TRH de curta duração (até 10 anos) e níveis mais altos de aptidão física apresentam os melhores resultados, inclusive, algumas das regiões mais suscetíveis a atrofia cerebral relacionada a idade - córtex pré-frontal e temporal - parecem ser mais sensíveis à esta combinação. Conclui-se que a interação entre a TRH de estrógeno e o aumento dos níveis de aptidão física, quando combinados, apresentam melhores resultados do que separadamente. 
Seguindo ainda o raciocínio a respeito da interferência hormonal causada pela atividade física, Mazzeo apud Santos (1998) relatam que o exercício físico provoca estresses no organismo promovendo ajustes em diferentes sistemas do corpo humano. Como resposta a este estresse o sistema nervoso simpático e as glândulas adrenais têm um papel predominante na resposta. O exercício físico induz a um aumento na produção de noradrenalina e dopamina e de alguns neuropeptídeos, como a endorfina (KHALSA, 1997). Outros hormônios participam da resposta adaptadora do organismo ao exercício e são: a adrenalina, ACTH, a vasopressina, os peptídeos opióides (IZQUIERDO citado por SANTOS, 1998).

Os exercícios aeróbios parecem ser os que surtem efeitos mais positivos em relação às melhorias cerebrais, e nas funções cognitivas e mentais (SHEPHARD, 2003; VAN BOXTEL et al. citados por MATSUDO, 2000; HANNA et al., 2001; COLCOMBE et al., 2003; MCAULEY, KRAMER e COLCOMBE, 2004; NETZ et al., 2005; KRAMER et al., 2005; KRAMER, ERICKSON E COLCOMBE, 2006).

Idosos que são mais bem condicionados aerobicamente tendem a perder menos tecidos nos córtex frontal, parietal e temporal, em função da idade (COLCOMBE et al, 2003). Outro estudo de Colcombe et al., citados por Kramer et al. (2005), relacionado a um treinamento aeróbico de seis meses, mostrou que houve um aumento da ativação do córtex parietal superior e dos giros médio-frontais.

Van Boxtel et al, citados por Matsudo (2000) estudaram a interação da potência aeróbia com tarefas demandantes de processos cognitivos, e verificaram que a velocidade cognitiva complexa teve uma interação com os níveis de potência aeróbica, o que sugere que a aptidão aeróbica pode agir nos processos cognitivo, por sua vez Shephard (2003), menciona exercícios aeróbios como associados à melhora do desempenho mental.

Também Hanna et al. (2001) expõem uma relação entre exercício físico e melhorias da função cognitiva. Em seu estudo, um grupo experimental participou de um programa de condicionamento físico com ênfase no metabolismo aeróbico que consistiu em uma caminhada três vezes por semana, com duração de 60 minutos. Como atividades complementares foram realizados exercícios de alongamento e flexibilidade articular. Os resultados revelaram que o grupo experimental melhorou significativamente na atenção, memória, agilidade motora, sendo significativo também à melhora de humor. Os dados sugerem que a participação em um programa de condicionamento físico aeróbio sistematizado pode ser visto como uma alternativa não medicamentosa para a melhora cognitiva em idosos não demenciados.

A manutenção de níveis de aptidão aeróbica mais altos talvez proteja o sistema nervoso das perdas e danos sofridos no decorrer de um processo de envelhecimento normal, bem como dos problemas de saúde relacionados a este processo. Inclusive, parece que mesmo pequenas intervenções de treinamento aeróbico possam iniciar a recuperação do cérebro envelhecido ao mesmo tempo em que pode melhorar a performance em diversas tarefas cognitivas (MCAULEY, KRAMER e COLCOMBE, 2004).

Já os exercícios de força, flexibilidade e programas de ioga, segundo Shephard (2003), não apresentaram os mesmos resultados quanto às funções cognitivas e mentais.

Contudo, a relevância da prática destas modalidades é comprovada ao se analisar a coordenação motora. Observa-se, com o envelhecimento, alteração negativa na velocidade e coordenação motora. Estas alterações, todavia, não atingem de forma exacerbada a realização de movimentos simples, mas sim os movimentos mais coordenados e complexos, que requerem maiores velocidades. Partes destas alterações podem decorrer de limitações periféricas como conseqüência de fatores musculares (MORA e PORRAS, 1998).

Neste ponto, o estudo realizado por Dias e Duarte (2005), põe-se a favor das atividades não aeróbicas (treinamento resistido, yoga, flexibilidade, etc.). Neste estudo foram analisados testes de coordenação motora, realizados entre os anos de 1997 a 2000, em mulheres idosas com idade entre 62 e 70 anos. Estas idosas realizavam exercícios físicos três vezes por semana (terça-feira: Dança e Musculação; quarta-feira: Biotonia e Ginástica; quinta-feira: Esportes e Atividades Lúdicas) com um volume de uma hora por dia. Os resultados obtidos com este levantamento indicam que a prática destas modalidades melhora ou mantém o nível 
de coordenação motora, retardando assim os efeitos do envelhecimento nesta habilidade. Além deste tipo de benefício, estas atividades, ressaltando-se o treinamento resistivo, é um modo importante de aumentar o nível de atividade física dos idosos (FLECK; KRAEMER, 1999), o que é um dos fatores chave relacionados ao envelhecimento com qualidade (SHEPHARD, 2003; NAHAS, 2001). Também Mcauley, Kramer e Colcombe (2004) apontam que indivíduos mais aptos fisicamente apresentam melhores desempenhos em testes que vão desde a percepção e cognição, a diferentes tarefas motoras.

Está claro que o treinamento aeróbico produz resultados efetivos no combate aos processos degenerativos do sistema nervoso relacionados à idade. Contudo, estes exercícios quando combinados aos exercícios de força e flexibilidade tendem a apresentarem efeitos mais positivos do que apenas os exercícios aeróbicos singularmente. Este efeito pode ser em virtude do aumento do fator de crescimento insulina-símile (IGF), um neuroprotetor que aumenta em resposta ao treino de força e está relacionado ao crescimento e diferenciação neuronal (KRAMER et al., 2005).

Referindo-se à intensidade da atividade física, o nível moderado parece ser o mais adequado para uma função neurológica apropriada (KHALSA, 1997; NETZ et al., 2005), como também, salienta Khalsa (1997), pode ser mais saudável do que níveis altos. Os efeitos dos exercícios físicos na cognição parecem ser segundo Mcauley, Kramer e Colcombe (2004), maiores quando a sessão de treinamento é superior a 30 minutos.

Contudo, Kleim, Jones e Schallert (2003), afirmam que não estão claro quais aspectos do exercício realmente contribuem como moderadores no envelhecimento do sistema nervoso. Contribuindo com esta idéia, tanto Netz et al. (2005), quanto Kramer et al. (2005) concluem que ainda não está definida a relação entre o tempo mínimo, o modo, a intensidade e a freqüência do treinamento físico na magnitude da resposta na cognição e no cérebro.

É importante salientar, também, a importância de se ter um histórico de vida ativo. Kramer, Erickson e Colcombe (2006), citam um estudo de Dik et al., onde estes autores atentam para este fato e sugerem que a relação inversa, entre os níveis de atividade física e as degenerações sofridas pelo sistema nervoso, pode se estender por um período de várias décadas. O estudo de Dik et al., foi de caráter retrospectivo, e questionou cerca de 1241 idosos acima de sessenta anos sobre suas atividades físicas quando tinham entre 15 e 25 anos. Interessantemente, os resultados apontaram que os homens que foram moderadamente ativos quando jovens apresentaram uma maior velocidade de processamento no decorrer da vida. Contribuindo, Rovio et al., também citado por Kramer, Erickson e Colcombe, indicam que hábitos de lazer, como a atividade física, pelo menos duas vezes por semana na meia-idade, estão associados à redução do risco de demência em idades mais avançadas.

A literatura apresenta resultados que induzem a uma relação, no mínimo, significativa, se não conclusiva, entra aptidão e treinamento físico e a saúde cerebral e cognitiva. Porém, os mecanismos que atuam nas entrelinhas dos benefícios do exercício físico na saúde cerebral e cognitiva não foram ainda bem estabelecidos e permanecem não esclarecidos (KLEIM, JONES e SCHALLERT, 2003; MCAULEY, KRAMER e COLCOMBE, 2004; VANCE et al., 2005; KRAMER, ERICKSON E COLCOMBE, 2006).

\section{Considerações finais}

O processo de envelhecimento do sistema nervoso parece ocorrer em virtude da uma programação genética (relógio biológico), entretanto, como citado anteriormente, este relógio pode ser retardado em virtude dos hábitos de vida, e outros fatores. No entanto, este processo não está totalmente esclarecido, fazendose assim necessárias mais pesquisas com o intuito de desvendá-lo.

AAtividade física pode ser considerada um fator moderador destas alterações, atuando de forma positiva em diversas delas. Os exercícios de caráter aeróbio parecem ser os que surtem efeitos mais positivos, contudo a combinação destes, com exercícios de força e flexibilidade parece possuir efeitos mais positivos ainda. A discussão deste assunto reflete a existência de uma forte correlação, entretanto há autores que a questionam. Contudo, encontram-se, na literatura, pistas substanciais que indivíduos fisicamente ativos possuem uma melhor performance cognitiva, eum envelhecimento cerebral mais saudável do que indivíduos inativos. 
Todavia, os mecanismos que atuam nas entrelinhas, os por quês, dos efeitos provocados pelo exercício físico na saúde cerebral permanecem não totalmente desvendados, estando ainda à espera de sua total elucidação. Em virtude disso mais pesquisas que visem esclarecer esta complexa relação devem ser realizadas, inclusive analisando a interferência do modo, intensidade, freqüência e tempo de treinamento físico na magnitude da resposta no cérebro.

Com isso, pode-se concluir que os benefícios da melhora dos níveis de aptidão física no idoso podem garantir um envelhecimento cerebral mais saudável. As pesquisas em neurociência devem prosseguir e a necessidade de se avaliar as influências do exercício físico no processo de envelhecimento cerebral fica, novamente, confirmada neste estudo.

\section{REFERÊNCIAS}

1. AZEVEDO, J.R.D. Distúrbios da memória: novas perspectivas. Publicado em junho, 2003. Disponível em: <http:// www.ficarjovemlevatempo.com.br/> Acesso em: novembro, 2004.

2. BERNHARDI M., R.. Envejecimento: Cambios Bioquímicos y Funcionales del Sistema Nervioso Central. Revista Chilena de Neuro-Psiquiatría. 43(4): pp. 297-304, 2005.

3. BREHER, L.; KRAMER, A.F.; PETERSON, M.S.; COLCOMBE, S.J.; ERICKSON, K.I.; BECIC, E. Testing the limits of cognitive plasticity in older adults: Application to attentional control. Acta Psychologica. In Press, 2006.

4. BORGE, M.J.N.; HERNÁNDEZ, M.G.; EGEA, M.P.T.Capítulo 2 - Proceso de Envejecer: Cambios Físicos, Cambios Psíquicos e Cambios Sociales in HERNÁNDEZ, M.G.; EGEA, M.P.T.; PÉRES, E.B. Enfermería Geriátrica. 2. ed. Masson, 1999.

5. CALINGASAN, N.Y.; GIBSON, G.E. Dietary restriction attenuates the neuronal loss, induction of heme oxygenase-1 and blood-brain barrier breakdown induced by impaired oxidative metabolism. Brain Research. 885(1): p. 62-69, 2000.

6. CANÇADO, F.A.X.; HORTA, M.L. Cap. 13 Envelhecimento Cerebral in FREITAS, E.V.; PY, L.; NERI, A.L.; CANÇADO, F.A.X.; GORZONI, M.L.; ROCHA, S.M. Tratado de Geriatria e Gerontologia. Rio de Janeiro: Guanabara Koogan, 2002, p.112127.

7. CARVALHO FILHO, E.T.; PAPALÉO NETTO, M. Geriatria, fundamentos, clínica e terapêutica. São Paulo - SP: Editora Atheneu, 2000.

8. CHEIK, N.C.; REIS, I.T.; HEREDIA, R.A.G; VENTURA, M.L.;
TUFIK, S.; HANNA, K.M.A.; MELLO, M.T. Efeitos do exercício físico e da atividade física na depressão e ansiedade em indivíduos idosos. Revista Brasileira de Ciência e Movimento. 11(2), 2003.

9. COLCOMBE, S.J.; ERICKSON, K.I.; RAZ, N.; WEBB.A.G.; COHEN, N.J.; MCAULEY, E.; KRAMER, A.F. Aerobic Fitness Reduces Brain Tissue Loss in Aging Humans. Journal Gerontology: Medical Scienses. 58A(1): p. M00-M00, 2003.

10. COSTA, A.J.S. A prática de atividades físicas direcionada à população idosa: cuidados, prescrições e benefícios. Lecturas: Educación Física e Deportes - revista digital. n.XX, 2005. Disponível em: <http://www.efdeportes.com/> Capturado em: Novembro de 2004.

11. DIAS, V.K. e DUARTE, P.S.F. Idoso: Níveis de Coordenação Motora sob Prática de Atividade Física Generalizada. Lecturas: Educación Física e Deportes - revista digital. n.89, 2005. Disponível em: <http://www.efdeportes.com/> Capturado em: Setembro de 2005.

12. DOHERTY, T.J.; VANDERVOORT, A.A.; TAYLOR, A.W.; BROWN, W.F. Effects of Motor Unit Loses on Strength in Older Men and Women. Journal of Applied Physiology. 74: p. 868-74, 1993.

13. ERICKSON, K.I.; COLCOMBE, S.J.; ELAVSKY, S.; MCAULEY, E.; KOROL, D.L.; SCALF, P.E.; KRAMER, A.F. Interactive Effects of Fitness and Hormone Treatment on Brain Health in Postmenopausal Women. Neurobiology of Aging. In Press, 2006.

14. FERRARI, E.A.M.; TOYODA, M.S.S.; FALEIROS, L.; CERUTTI, S.M. Plasticidade Neural: Relações com o Comportamento e Abordagens Experimentais. Psicologia: Teoria e Pesquisa. 17(2): p. 187-194, 2001.

15. FLECK, S.J.; KRAEMER, W.J. Fundamentos do Treinamento de Força Muscular. 2. ed. Porto Alegre - RS: Artmed, 1999.

16. FOSS; M.L.; KETEYIAN, S.J.F. Bases fisiológicas do exercício e do esporte. Rio de Janeiro - RJ: Editora Guanabara Koogan S.A., 2000.

17. GEIS, P.P. Atividade física e saúde na terceira idade. Porto Alegre - RS: Artmed, 2001.

18. GIOVANNELLI, L.; DECOROSI, F.; DOLARA, P.; PULVIRENTI, L. Vulnerability to DNA damage in the aging rat substantia nigra: a study with the comet assay. Brain Research. 969(1-2): p. 244-247, 2003.

19. GRILL, J.D; RIDDLE, D.R. Age-related and laminar-specific dendritic changes in the medial frontal cortex of the rat. Brain Research. 937(1-2): p. 08-21, 2002.

20. GUYTON, A.C. Fisiologia humana. Rio de Janeiro - RJ: Guanabara Koogan, 6. ed., 1988.

21. HANNA, K.M.A.; RÍNEL,A.G.H.; BUENO, O.F.A.; MELLO, 
M.T. Alterações cognitivas em idosas decorrentes do exercício físico sistematizado. Revista da Sobama. 6(1), 2001.

22. HAYFLICK, L. Como e Por Que Envelhecemos. Campus, 2. ed, 1997.

23. HEATH, G.W. Programação de exercícios para idosos. ACSM - American College of Sports Medicine: Prova de Esforço \& Prescrição de Exercício. Rio de Janeiro - RJ: Revinter, 1994.

24. KARUZA, J. Cap. 16 Aspectos Psicológicos do Envelhecimento in CALKINS, E.; FORD, A.B.; KATZ, P.R. Geriatria Prática. Rio de Janeiro: Revinter, 1997.

25. KHALSA, D.S. Longevidade do cérebro. Rio de Janeiro RJ: Editora Objetiva, 1997 (edição revista).

26. KLEIN, J.; JONES, T.A.; SCHALLERT, T. Motor Enrichment and the Induction of Plasticity Before or After Brain Injury. Neurochemical Research. 28(11): p.1757-1769, 2003.

27. KRAMER, A.F.; HAHN, S.; COHEN, N.; BANICH, M.; MCAULEY, E.; HARRISON, C. et al. Aging Fitness and Neurocognitive Function. Nature. 400: p. 418-419, 1999.

28. KRAMER, A.F.; COLCOMBE, S.J.; MACAULEY, E.; SCALF, P.E.; ERICKSON, K.I. Fitness, Aging and Neurocognitive Function. Neurobiology of Aging. 26S: p. S124S127, 2005.

29. KRAMER, A.F.; ERICKSON, K.I.; COLCOMBE, S.J. Exercise, Cognition and the Aging Brain. Journal of Applied Phisiology. In Press, 2006.

30. KRAMER, A.F.; MADDEN, D.J. Attention in: CRAIK, F.I.M.; SALTHOUSE, T.A. The Handbook of Aging and Cognition. 3. ed. (in press) Mahwah, NJ: Erlbaum, 2006.

31. LEITE, P.F. Aptidão física, esporte e saúde. São Paulo - SP: Robe Editorial, 2000, 3. ed.

32. LEHNINGER, A.L. Princípios da Bioquímica. São Paulo SP: Sarvier, 6a.impressão, 1990.

33. LENT, R. Cem Bilhões de Neurônios: conceitos fundamentais de neurociência. São Paulo - SP: Atheneu, 2001.

34. LEXELL, J. Evidence for Nervous System Degeneration with Advancing Age. Journal of Nutrition - American Society For Nutritional Sciences. 127: p. 1011S-1013S, 1997.

35. MACAULEY, E.; KRAMER, A.F.; COLCOMBE, S.J. Cardiovascular Fitness and Neurocognitive Function in Older Adults: a brief review. Brain, Behavior and Immunity. 18: p. 214-220, 2004

36. MATTSON, M.P. Neuroprotective signaling and the aging brain: take away my food and let me run. Brain Research. 886(1-2): p. 47-53, 2000.

37. MATSUDO, S.M.; MATSUDO, V.K.R.; BARROS NETO, T.L. Efeitos benéficos da atividade física na aptidão física e saúde mental durante o processo de envelhecimento. Revista
Brasileira deAtividade Física e Saúde. 5(2): p. 60-76, 2000.

38. MORA, F.; PORRAS, A. Cap. 36 - Procesos Involutivos Del Sistema Nervioso in DELGADO, J.M.; FERRÚS, A.; MORA, F.; RUBIA, F.J. Manual de Neurociência. Madri: Sintesis, 1998 p. 915-927.

39. MORIGUCHI, Y.; MORIGUCHI, E.H. Biologia Geriátrica Ilustrada. São Paulo: Fundo Editorial BYK, 1988.

40. MOUTON, P.R.; LONG, J.M.; LEI, D.L.; HOWARD, V.; JUCKER, M.; CALHOUN, M.E.; INGRAM, D.K. Age and gender effects on microglia and astrocyte numbers in brains of mice. Brain Research. 956(1): p. 30-35, 2002

41. NAHAS, M.V. Atividade física, saúde e qualidade de vida: conceitos e sugestões para um estilo de vida ativo. Londrina: Midiograf, 2001.

42. NETZ, Y.; WU, M.J.; BECKER, B.T.; TENENBAUM, G. Physical Activity and Psychological Well- Being in Advanced Age: A Meta-Analysis of Interventions Studies. Psychology and Aging. 20(2): p. 272-284, 2005.

43. OLIVEIRA, G.M. Cap. 4 Neurorradiologia do Envelhecimento in PEREIRA, C.U.; ANDRADE FILHO, A.S. Neurogeriatria. Rio de Janeiro: Revinter, 2001.

44. OLIVEIRA, R.J.; FURTADO, A.C. Envelhecimento, Sistema Nervoso e o Exercício Físico. Lecturas: Educación Física e Deportes - revista digital. n.15, 1999. Disponível em: <http:// www.efdeportes.com/> Capturado em: Setembro de 2005.

45. RESUEHR, D.; OLCESE, J. Caloric restriction and melatonin substitution: Effects on murine circadian parameters. Brain Research. 1069(1): pp. 198-206, 2006.

46. SANTOS, D.L.; MILANO, M.E.; ROSAT, R. Exercício físico e memória. Rev. Paulista de Educação Física. 12(1), 1998.

47. SCHALLERT, T.; WOODLEE, M.T. Brain-dependent Movements and Cerebral-spinal Connections: Key Targets of Cellular and Behavioral Enrichment in CNS Injury Models. Journal of Rehabilitation Research and Development. 40(4): p. 9-18, 2003.

48. SHEPHARD, R.J. Envelhecimento, atividade física e saúde. São Paulo - SP: editora Phorte, 2003.

49. SHI, L.; POE, B.H.; LINVILLE, M.C.; SONNTAG, W.E.; BRUNSO-BECHTOLD, J.K. Caloric restricted male rats demonstrate fewer synapses in layer 2 of sensorimotor cortex. Brain Research. 931(1): p. 32-40, 2002.

50. VANCE, D.E.; WADLEY, V.G; BALL, K.K.; ROENDER, D.L.; RIZZO, M. The Effects of Physical Activity and Sedentary Behavior on Cognitive Health in Older Adults. Journal of Aging and Physical Activity. 13(3), 2005.

51. VARGAS, S. Metodologia de Ensino-Aprendizagem para Pessoas Idosas. Lecturas: Educación Física e Deportes - revista digital. n. 39, 2001. Disponível em: <http:// www.efdeportes.com/> Capturado em: Setembro de 2005. 